\title{
Web-Based Information System on Travel Ticket Booking
}

\author{
M R Fauji ${ }^{1}$, D Fatimah ${ }^{2}$ \\ \{rizkifauji@mahasiswa.unikom.ac.id ${ }^{1}$, dina.fatimah@email.unikom.ac.id $^{2}$ \}
}

Department of Information System, Universitas Komputer Indonesia, Bandung, Indonesia ${ }^{1}$, Department of Interior Design, Universitas Komputer Indonesia, Bandung, Indonesia ${ }^{2}$

\begin{abstract}
The purpose of this study is to design a web-based information system for booking travel tickets and increasing the effectiveness of purchasing travel tickets. To support this research, the author uses descriptive methods for several travel services providers. The results show that there are still some things that become less efficient when consumers are still using conventional methods. From these results, the author still gets many travel service providers who still have difficulty processing ticket booking data. This is because many travel service providers do not trust the internet or information systems that can process order data more effectively and efficiently. Therefore, with a travel ticket ordering information system, it is easier for consumers to order tickets and make it easier for travel service providers to process consumer data.
\end{abstract}

Keywords: Information System, Travel Service

\section{Introduction}

At this time, the development of information technology in this globalization era is very rapid. With the development of information technology and information systems, information can be obtained quickly by users. Currently there are many information systems that provide convenience and fast service for users, and the information system is a part of the development of information technology. An information system is needed in every business organization, which functions as a supporter of information services [1]. Information systems must also be developed. There are many system development methods, including the waterfall method. Modeling in a software is something that is done in the initial stages. In software engineering, it is actually still possible without modeling. However, this can no longer be done in a software industry. Modeling in software is something that must be done in the early part of engineering, and this modeling will affect the work in software engineering.

The software process model is still the object of research, but now there are many common models or paradigms that are different from software development [2]. Advantages of the Waterfall method include being simple and easy to implement, easy to set up, and suitable for small projects [3]. The concept of the Waterfall is to describe the development of the system in a linear and sequential manner. Waterfall has several phases in each development cycle where each phase has a different purpose in the process [4]. The travel and entertainment sector has experienced extreme changes in the past century. The progress of online services has made it easier and more time and cost effective for tourists to make their travel arrangements by themselves, rather than relying on travel agent services, etc. Thus, tourists can search the Internet for available travel products and services, such as airline tickets, hotel rooms and rental cars [5]. A good travel agent information system must be integrated with a credit card or other payment method [6]. In making an information system, there must always be a data base according to system requirements so that all data is well integrated [7]. This information system can make business more advanced [8]. With the creation of this information system, it will make the company more profitable and reduce the cost of advertising [9]. 
The purpose of making an information system with this waterfall method is to create a ticket booking service at a travel company which makes it easy to order, make reports, and check the departure schedule of the travel [10].

The method used in this research is the qualitative method, specifically the descriptive method as a basis for the determination of the relevant variables needed and the waterfall development process in the development of the web page-based information system.

\section{Material and Methods}

In this study the author uses a descriptive method to find out variables related to travel service providers and usage. Previous research related to information systems on travel ticket booking are used so that the web-based information system can be designed for booking travel tickets.

\section{Results and Discussion}

The method that will be carried out in the design of information systems on travel agents that will be made is to apply the concept of waterfall development in the development process. Waterfall development is a development model and customers can interact with each other during system development. Waterfall method is a sequential software development process, where progress is directed as it continues to flow down (like a waterfall) through phases of planning, modelling, implementation (construction), and testing.

\subsection{Stages of the Waterfall Method}

In its development the waterfall method has several coherent steps: requirements, design, implementation, verification and maintenance. The following are the steps:

1. The system requirements or specifications stage is a system needs analysis that is made in a form that can be understood by the client and developer staff. At this stage the client or user explains all boundaries and goals and determines what is desired from the system. After the specification document is approved, the document becomes a work contract between the client and the developer.

2. The next stage is design. At this stage, the developer will produce the system architecture as a whole and determine the flow of software to a detailed algorithm.

3. Then the implementation phase, which is the stage where the overall design is changed to the program code. The resulting program code is still in the form of a module which will then be integrated into a complete system to ensure that the software requirements are met.

4. The next stage is verification by the client. The client tests whether the system is in accordance with the agreed contract.

5. The last stage is maintenance which includes installation and process improvement of the system in accordance with the contract.

\subsection{System Analysis}

\subsubsection{Problem Analysis}

The current travel ticket system at travel agent is a conventional ticket booking system where prospective passengers must immediately come to the ticket purchasing booth or request a departure schedule and then order the ticket to be purchased and then make a transaction. Such methods are less effective and efficient. Based on this, the development of a web-based information system on travel ticket booking can be one solution to improve the quality of business where the benefits of developing a web-based information system on travel ticket booking are where the scope of business can become wider. Initially for consumers it is a waste of a lot of phone credit just to ask for departure schedules and availability of tickets. With this application, all information can be accessed easily such as departure schedule, ticket 
availability and other information about travel agents. The development of this web-based application is expected to be able to overcome the problems above.

\subsubsection{System Design}

At this stage the system design process will be carried out from design to applying the results of the analysis into the form of software development and the coding stage will be carried out or the stage of building a system that interprets the design created into the code sequence. The visual design is made simple so that it is easy to understand.

\subsubsection{Design}

Designing in this study uses an application for a mock-up design called balsamic. To represent the results of system analysis and system requirements, the design is made in several display designs. (see Figure 1-7).

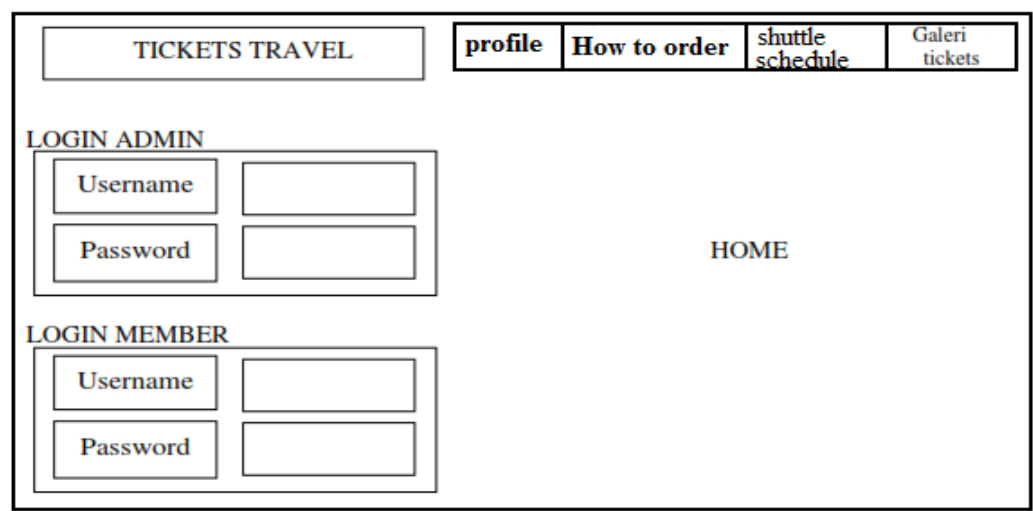

Fig 1. User login page.

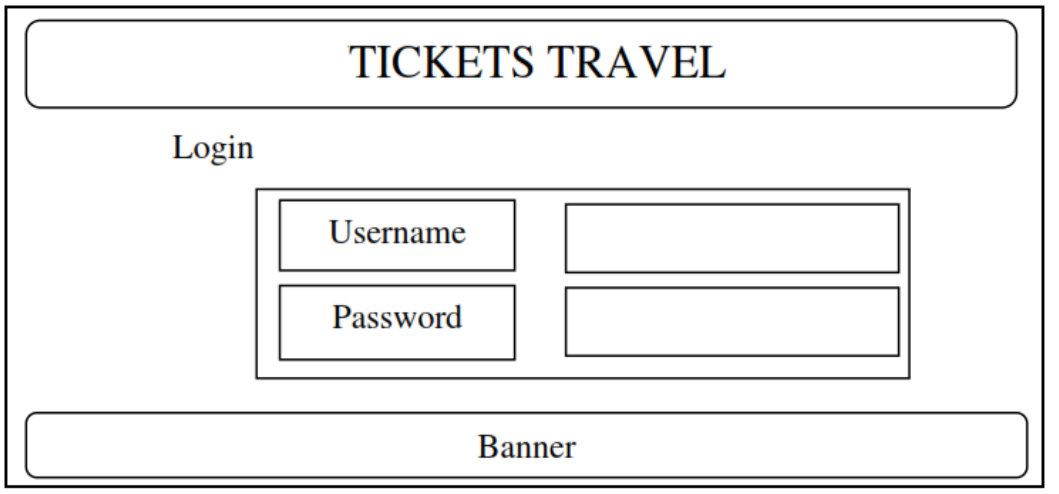

Fig 2. Login Input. 


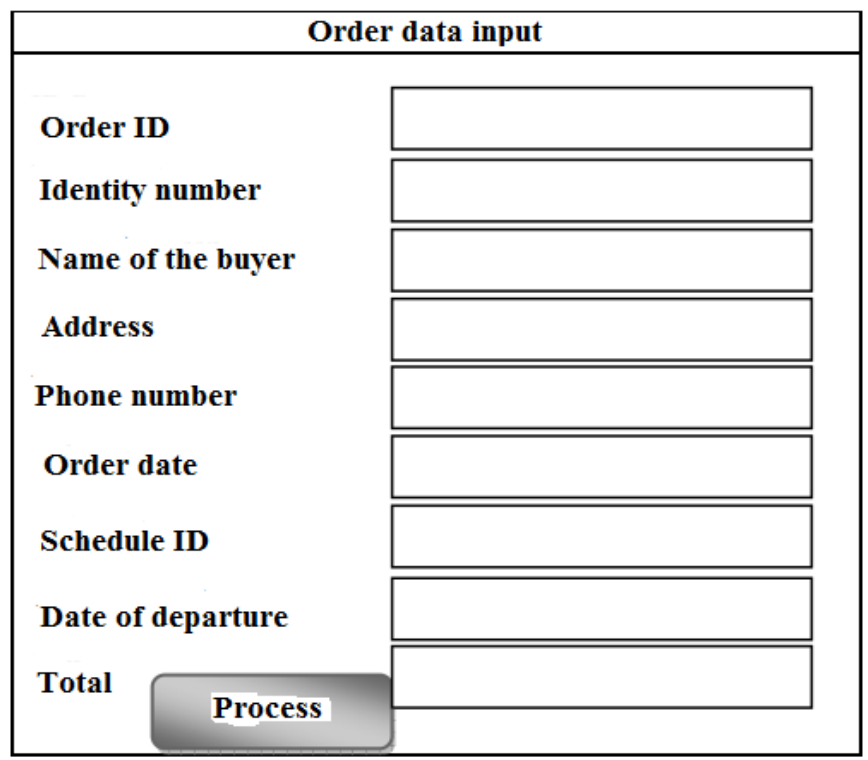

Fig 3. Search input.

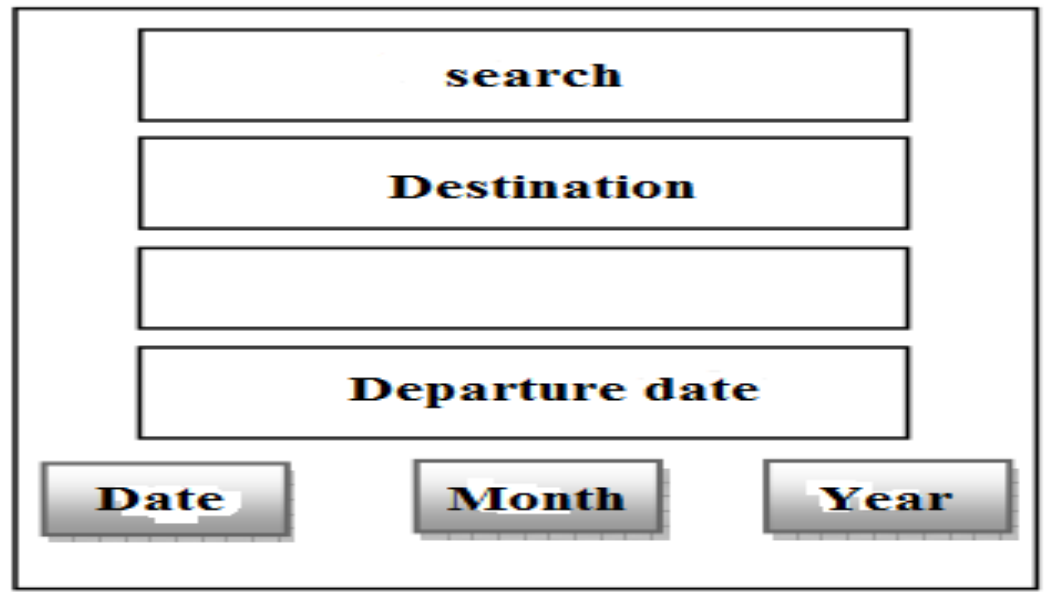

Fig 3. Order data input. 


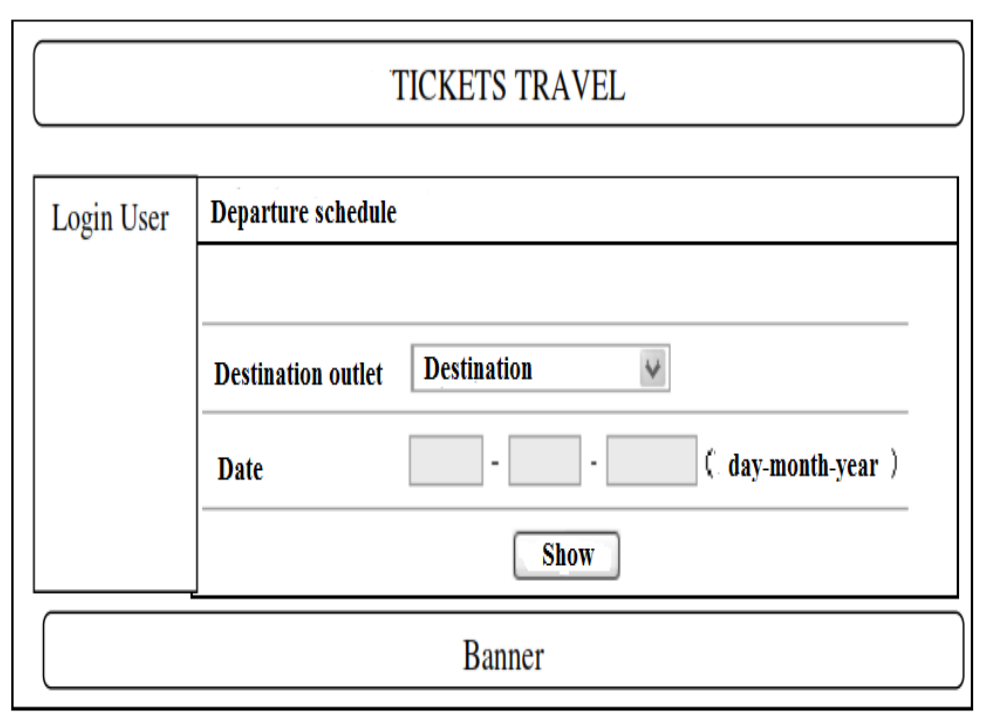

Fig 4. Schedule search input.

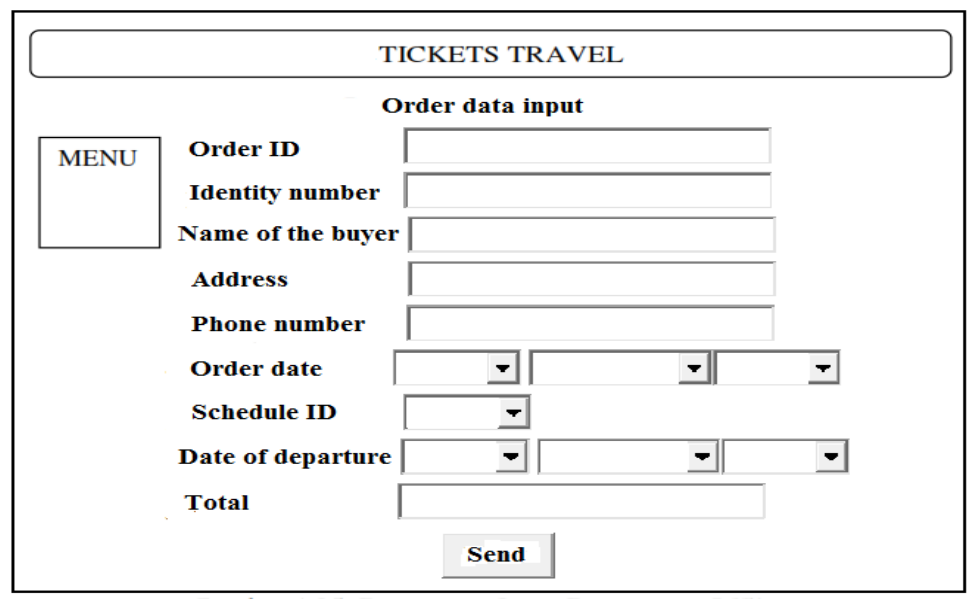

Fig 5. Offline data input ordering.

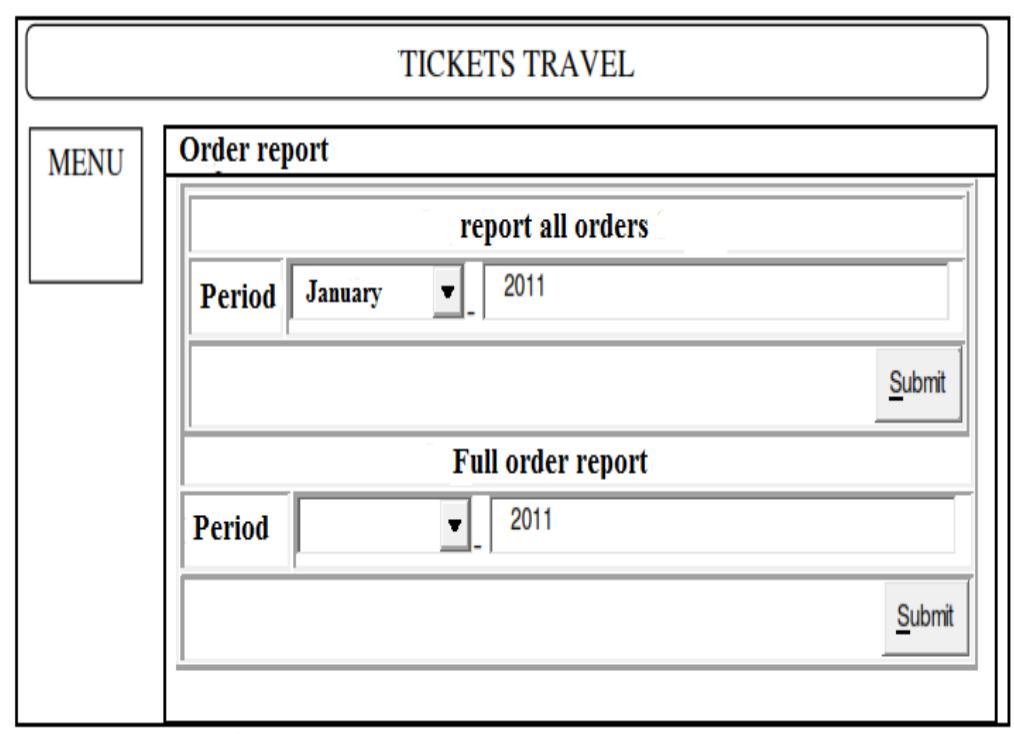

Fig 6. Order report. 


\subsubsection{System Development Stage (Coding)}

In carrying out system maintenance or representing the design in the line of code, the tools for the process of writing code include Sublime 3, MySql as a Database Management System, HTML, php, Javascript, and CSS which are used to design interfaces and implement existing functions.

\subsubsection{System Testing}

At this stage the testing of the system that has been built is done where the results of the tests show that the system is running well and where all the functions that have been built are running as expected.

\section{Conclusion}

Based on the results of research conducted in the design of this application it can be concluded that the application that will be built will be able to increase the effectiveness and efficiency of activities in a travel company and increase the number of consumers. The number of consumers can increase due to an increase in the scope of the business. In addition to the increase in the business system scope, it can also provide better services than before because the system built can meet the needs of consumers, namely that consumers can access all the information needed and make it easier for consumers to order tickets to travel.

Acknowledgements. Thank you for those who helped provide data to complete this paper. I hope this paper is useful for its readers

\section{References}

[1] Rainer, R. K., Cegielski, C. G. : Splettstoesser-Hogeterp, I., \& Sanchez-Rodriguez, C. : Introduction to information systems. John Wiley \& Sons. 2013

[2] Bassil, Y. A simulation model for the waterfall software development life cycle. arXiv preprint arXiv:1205.6904. 2012

[3] Balaji, S., \& Murugaiyan, M. S. Waterfall vs. V-Model vs. Agile : A comparative study on SDLC. International Journal of Information Technology and Business Management, 2(1), 26-30. 2012

[4] Cobb, C. G. : The project manager's guide to mastering Agile: Principles and practices for an adaptive approach. John Wiley \& Sons. (2015)

[5] Altman, J., Fredericks, M., Csontos, A., Lore, M., Love, J., Harris, B., ... \& Elliott, B. : U.S. Patent Application No. 11/763,562. (2008)

[6] Vance, A., Balch, K., Vochatzer, K., Sawtell, C., \& Williams, S. : U.S. Patent Application No. 11/438,627. (2006)

[7] C Coronel, S Morris. : Data and Information Management Database Systems: Design, Implementation, \& Management, 11th Edition : Cengage Learning pp.35-46.

[8] Soegoto, Eddy soeryanto. : Enterpreneurship Menjadi Pebisnis Ulung PT Elex Media Komputindo, Jakarta:Kompas Gramedia. (2014)

[9] Tagawa, R. S. . U.S. Patent No. 5,732,398. Washington, DC: U.S. Patent and Trademark Office. (1998)

[10] Wijaya, C. P.,: Satoto, K. I., \& Isnanto, R. R.). Perancangan Sistem Informasi Pemesanan Tiket Travel Berbasis Web. Transmisi, 15(2), 79-86. (2013) 